\title{
The COVID-19 Outbreak and Oil Stock Price Fluctuations: Evidence From China
}

\author{
Yue Zhang ${ }^{1}$ a \\ ${ }^{1}$ Department of Finance, Huazhong University of Science and Technology, China \\ Keywords: arch, oil stock price fluctuation, covid-19, china \\ https://doi.org/10.46557/001c.27019
}

\section{Energy RESEARCH LETTERS}

Vol. 2, Issue 3, 2021

This study explores the relation between Chinese oil stock price volatility and the COVID-19 pandemic using an autoregressive conditional heteroskedasticity model and its generalization. We show that the COVID-19 outbreak has a positive and weakly persistent impact on oil stock volatility.

\section{Introduction}

The COVID-19 outbreak has generated serious challenges for the global economy. In particular, financial market risk and volatility heightened (Chen et al., 2020; Haroon \& Rizvi, 2020). For example, the stock market in the United States triggered circuit breakers three times in one week between March 9 and March 16, 2020. ${ }^{1}$ An extensive literature empirically tests the effects of COVID-19 on the stock market and explores the transmission mechanisms. Ftiti et al. (2021) document that non-fundamental news, rather than fundamental macroeconomic news, matters for the stock market during the COVID-19 pandemic. News about the number of deaths and cases related to the pandemic affects investor pessimism, thereby leading to an increase in stock market volatility and a decrease in stock market liquidity (Ftiti et al., 2021). Moreover, the degree of volatility spillover remains extremely high during the coronavirus recession, and emerging markets are the main ones subject to risk in the 2020 stock market crash (Li, 2021).

Oil price volatility is considered very important, since it predicts stock market returns and can affect global industrial production (Devpura \& Narayan, 2020). Since the COVID-19 outbreak, its influence on oil prices has attracted wide attention. It is now confirmed that increases in the numbers of cases and deaths lead to increased oil price volatility (Devpura \& Narayan, 2020) and could decrease oil demand and oil prices (Qin et al., 2020). Moreover, the magnitude of the effect increases as the cases of infection reaches a threshold (Narayan, 2020).

In this paper, we explore oil price volatility in China, because it is one of the world's largest oil consumers (Xia et al., 2019). In addition, increases in oil prices can potentially lead to inflation in China (Chen et al., 2020). In this regard, we find that China provides a perfect setting to better understand how the pandemic influences oil prices. To examine the impact of the COVID-19 pandemic on the Chinese oil price index, we employ autoregressive conditional heteroskedasticity (ARCH) models and their variants. We find that the COVID-19 outbreak made oil stock prices more volatile. However, since the Chinese government enacts measures to avoid the influence of the pandemic, the volatility of the oil stock price index has declined. This finding will help individual countries and regions to develop policies to mitigate the dramatic impact of similar events on their oil markets and even economies.

This paper contributes to the research that explores the impact of COVID-19 on the volatility characteristics of China National Petroleum Corporation stock. We also propose corresponding policy recommendations.

\section{Data and Methodology}

\section{A. Data}

This study examines the impact of oil stock price volatility induced by COVID-19, using Chinese oil industry stocks from July 8, 2019, to July 5, 2021. To eliminate the linear trend factor and obtain a smooth series, we perform firstorder difference regression on the oil stock price index, oilindex. We choose July 8, 2019, as the base period for calculating the index. Since the daily stock data have missing values, we use the previous values of the series to fill in missing values. We examine listed companies whose business scope includes oil production and obtain their daily stock closing prices from the China Stock Market \& Accounting Research database.

Table 1 presents the results of the descriptive statistics. The average of first difference in oilindex is -0.001, implying a decreasing trend in the oil stock index during our sam-

\footnotetext{
a Corresponding author: Yue Zhang, School of Economics, Huazhong University of Science and Technology, Wuhan 430074, China; email: zhangyue0521@hust.edu.cn

1 See the information at http://www.xinhuanet.com/fortune/2020-03/19/c 1125734270.htm.
} 
Table 1. Descriptive Statistics

\begin{tabular}{|c|c|c|c|c|c|}
\hline Statistic & Obs & Mean & Min & Max & SD \\
\hline oilindex & 728 & -0.001 & -0.086 & 0.056 & 0.012 \\
\hline Statistic & P10 & P25 & Median & P75 & P90 \\
\hline oilindex & -0.015 & -0.006 & -0.001 & 0.004 & 0.013 \\
\hline
\end{tabular}

This table reports the results of descriptive statistics for the main variables in this paper.

ple period. The maximum and minimum values are 0.056 and -0.086 , which means that the daily oil stock index varies considerably during our sample period.

Figure 1 shows the change in oilindex from July 8, 2019, to July 5 , 2021. It shows that oilindex is subject to volatile clustering and fluctuates more significantly between December 2019 and July 2020 than in other periods. According to a related report by Xinhua News Agency, the first onset of the new coronavirus pneumonia appeared in December 2019 . $^{2}$ We assume that the volatility of the oil stock price index will increase with the intensity of the COVID-19 outbreak.

\section{B. Autoregressive Conditional Heteroskedasticity}

The autoregressive conditional heteroskedasticity model and its generalizations are commonly used to analyze energy market volatility (Alberola, 2007; Jiang et al., 2019; Saghaian et al., 2018). In this paper, we therefore estimate ARCH models and their generalizations to analyze the volatility of daily oil stocks. These models include ARCH, generalized ARCH (GARCH), threshold GARCH (TGARCH), and GARCH using $t$-distributed perturbation terms (GARCHt). The ARCH(p) model takes the following form:

$$
\begin{gathered}
\text { oilindex }_{t}=c h_{t} \varepsilon_{t} \\
\operatorname{ch}_{t}^{2}=\alpha_{0}+\alpha_{1} \text { oilindex }_{t-1}^{2}+\ldots+\alpha_{p} \text { oilinde }_{t-p}^{2}
\end{gathered}
$$

where oilindex $x_{t}$ denotes the oil stock index at time $t, c h_{t}$ is the conditional heteroskedasticity, and $\left\{\varepsilon_{t}\right\}$ is a sequence of independent and identically distributed random variables with mean zero and variance one, which is usually assumed to obey the standard normal distribution.

To ensure the conditional heteroskedasticity of the data, that is, that we can use the ARCH model, we plot the autocorrelations and partial autocorrelations for the available data and perform Q-tests on them. The results show autocorrelation in the squared series of ordinary least squares residuals, so the $\mathrm{ARCH}(\mathrm{p})$ model and its generalizations can be used for our analysis. According to the likelihood ratio and Akaike information criterion (AIC), we determine the lag order of the ARCH model to be two, that is, we build the models $\operatorname{ARCH}(2), \operatorname{GARCH}(2,1)$, and so on. Table 2 shows the results of the above models.
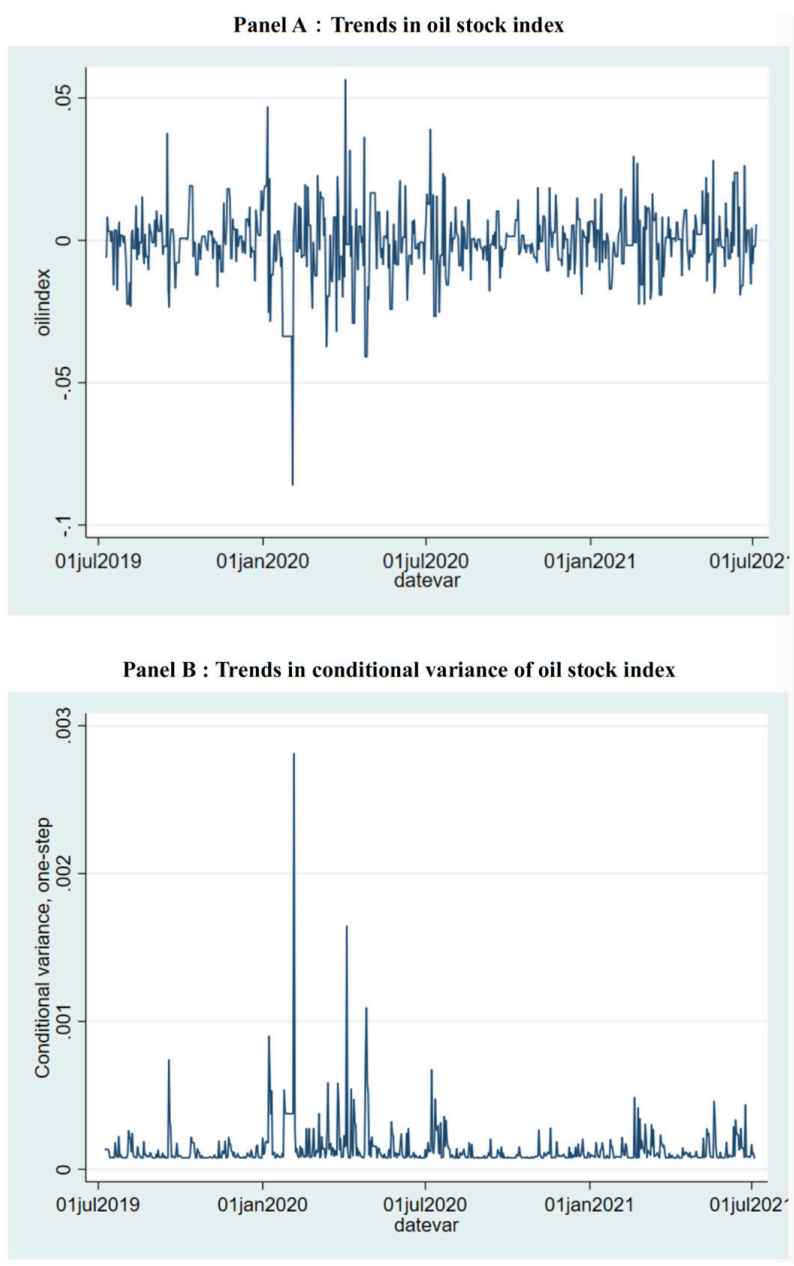

Figure 1. Trends in oil stock index and its conditional variance

Panel A shows the trend of the oil stock index over time. Panel B shows the trend of the conditional variance of the oilindex estimated according to the TARCH $(2,1)$ model over time.

\section{Results}

\section{A. Model Results}

Panels A and B of Table 2 show the results of the models cited above. The coefficient of 0.199 in the first column of the first row is less than one, indicating that only $19.9 \%$ of the variance shocks in the current period remain in the next 
Table 2. Results from the volatility model

\begin{tabular}{|c|c|c|c|c|}
\hline & (1) & $(2)$ & (3) & (4) \\
\hline & $\mathrm{ARCH}(2)$ & $\operatorname{GARCH}(2,1)$ & $\operatorname{TGARCH}(2,1)$ & GARCHt $(2,1)$ \\
\hline & & Panel A & & \\
\hline \multirow[t]{2}{*}{ L.oilindex } & $0.199^{* * *}$ & $0.217^{* * *}$ & $0.259^{* * *}$ & $0.329^{* * *}$ \\
\hline & $(0.0241)$ & $(0.0251)$ & $(0.0322)$ & $(0.0265)$ \\
\hline \multirow[t]{3}{*}{ L2.oilindex } & 0.0274 & $0.120^{* * *}$ & $0.0988^{* *}$ & $0.140^{* * *}$ \\
\hline & $(0.0355)$ & $(0.0372)$ & $(0.0402)$ & $(0.0326)$ \\
\hline & & Panel B & & \\
\hline \multirow[t]{2}{*}{ L2.arch } & $0.449^{* * *}$ & $0.0901^{* * *}$ & $0.0708^{* * *}$ & $0.288^{* *}$ \\
\hline & (0.0498) & $(0.0138)$ & $(0.0121)$ & $(0.135)$ \\
\hline \multirow[t]{2}{*}{ L.garch } & & $0.871^{* * *}$ & $0.850^{* * *}$ & $0.758^{* * *}$ \\
\hline & & $(0.0165)$ & $(0.0185)$ & $(0.0542)$ \\
\hline \multirow[t]{2}{*}{ L.tarch } & & & $0.0963^{* * *}$ & \\
\hline & & & $(0.0231)$ & \\
\hline & & Panel C & & \\
\hline $\mathrm{N}$ & 726 & 726 & 726 & 726 \\
\hline AIC & -4532.53 & -4562.69 & -4586.73 & -4667.01 \\
\hline $\mathrm{BIC}$ & -4509.59 & -4535.17 & -4554.62 & -4634.9 \\
\hline
\end{tabular}

This image shows Results from the volatility model. Panel A shows the estimation results of Equation 1. L.oilindex is the information on the change in the oil index obtained from the first period, and L2.oilindex is the information on the change in the oil index obtained from the second period. Panel B shows the estimation results of Equation 2. L2.arch is the information on the change in the oil index obtained from the first two periods. L.garch is the expected variance of the first period. L.tarch is the L.garch term that takes into account the asymmetric effect of good and bad news and is equal to L.garch when the perturbation term is negative and to 0 when the perturbation term is positive. Panel C shows the results of the model selection criteria. AIC and BIC represent Akaike Information Criterion and Bayesian Information Criterion. The robust standard errors are reported in parentheses. * * * $* *$ and $*$ represent statistical significance at the $1 \%, 5 \%$ and $10 \%$ levels, respectively.

period. We can thus see that the persistence of oil price fluctuations in China is weak. This phenomenon could be related to China's oil price mechanism: refined oil products in China are priced by each enterprise under the maximum retail price limit set by the National Development and Reform Commission of the People's Republic of China. This pricing mechanism has slowed down the drastic fluctuations of oil stock prices and significantly decreased financial market uncertainty surrounding domestic oil product price adjustments (Wen et al., 2018; Xiao et al., 2018). The results also show that the fluctuation of oil prices in China is mainly influenced by the international oil market.

The results in the fourth column in Table 2 on $\operatorname{TGARCH}(2,1)$ indicate an asymmetric effect on the oil stock price index. This implies that the effect of good news on the volatility of Chinese oil stock price is greater than the effect of bad news, which is consistent with Xiao et al. (2018).

\section{B. Robustness Checks}

Because the oil stock price index has a thick tail (Wang et al., 2020; Yu et al., 2020), low-probability events are more likely than in the case of a normal distribution. To ensure the robustness of the results, we build a GARCHt model where the perturbation terms obey a t-distribution. The results remain significant and are presented in the fifth column of Table 2 .

\section{Volatility Results}

Panel C of Table 2 shows the results of the model selection criteria. Since the AIC and the Bayesian information criterion (BIC) of $\operatorname{TGARCH}(2,1)$ are minimized, the TGARCH(2,1) model is the best-performing model. The conditional heteroskedasticity of the selected model is considered a proxy variable for the volatility of China's petroleum stock price index. Figure 2 illustrates its volatility over time.

<Insert Figure 2 here>

As we can see in Figure 2, the volatility in the oil stock index began in late December 2019, which is when the first COVID-19 cases appeared. ${ }^{3}$ The volatility of the oil stock index also decreases significantly from late June 2020 as the outbreak was effectively contained. This finding suggests that the COVID-19 outbreak had a knock-on effect on the oil stock index, causing a significant increase in volatility, which returned to normal after the COVID-19 pandemic was under control. This finding is consistent with the study of Devpura and Narayan (2020): death increases the volatil- 
ity of oil prices and changes as the number of infections increases, in line with Narayan (2020).

\section{Conclusions}

In this paper, we investigate the volatility of Chinese oil stock prices using an ARCH model. We find that the COVID-19 outbreak made the volatility of the China National Petroleum share price index more pronounced. Due to China's oil pricing mechanism, the current impact of the pandemic on oil prices is short-lived.

Using the results of this paper, we find that appropriate interventions in oil prices by government agencies can help reduce oil market movements and ensure healthy economic development. At the same time, in the face of the impact of black swan events such as COVID-19 on the oil stock index, governments should cooperate in a timely manner to take measures to reduce the volatility of the stock index. 


\section{REFERENCES}

Alberola, R. (2007). Estimating Volatility Returns Using ARCH Models. An Empirical Case: The Spanish Energy Market[J]. Lecturas de Economia, 66, 251-276.

Chen, J., Zhu, X., \& Li, H. (2020). The pass-through effects of oil price shocks on China's inflation: A time-varying analysis. Energy Economics, 86, 104695. https://doi.org/10.1016/i.eneco.2020.104695

Devpura, N., \& Narayan, P. K. (2020). Hourly oil price volatility: The role of COVID-19. Energy RESEARCH LETTERS, 1(2), 13683.

Ftiti, Z., Ameur, H. B., \& Louhichi, W. (2021). Does nonfundamental news related to COVID-19 matter for stock returns? Evidence from Shanghai stock market. Economic Modelling, 99, 105484. https://doi.org/10.10 16/j.econmod.2021.03.003

Haroon, O., \& Rizvi, S. A. R. (2020). COVID-19: Media coverage and financial markets behavior-A sectoral inquiry. Journal of Behavioral and Experimental Finance, 27, 100343. https://doi.org/10.1016/i.jbef.202 0.100343

Jiang, Y., Jiang, C., Nie, H., \& Mo, B. (2019). The timevarying linkages between global oil market and China's commodity sectors: Evidence from DCC-GJRGARCH analyses. Energy, 166, 577-586. https://doi.or g/10.1016/i.energy.2018.10.116

Li, W. (2021). COVID-19 and asymmetric volatility spillovers across global stock markets. The North American Journal of Economics and Finance, 58, 101474. https://doi.org/10.1016/j.najef.2021.101474

Narayan, P. K. (2020). Oil price news and COVID-19-Is there any connection? Energy RESEARCH LETTERS, 1(1). https://doi.org/10.46557/001c.13176
Qin, M., Zhang, Y. C., \& Su, C. W. (2020). The essential role of pandemics: A fresh insight into the oil market. Energy Research Letters, 1(1), 13166.

Saghaian, S., Nemati, M., ... Walters, C. (2018). Asymmetric price volatility transmission between US biofuel, corn, and oil markets[J]. Journal of Agricultural and Resource Economics, 43(1), 46.

Wang, J., Jiang, Y., Zhu, Y., \& Yu, J. (2020). Prediction of volatility based on realized-GARCH-kernel-type models: Evidence from China and the U.S. Economic Modelling, 91, 428-444. https://doi.org/10.1016/j.econ mod.2020.06.004

Wen, X., Bouri, E., \& Roubaud, D. (2018). Does oil product pricing reform increase returns and uncertainty in the Chinese stock market? The Quarterly Review of Economics and Finance, 68, 23-30. https://doi.org/10.1016/j.qref.2017.08.003

Xia, Y., Kong, Y., Ji, Q., \& Zhang, D. (2019). Impacts of china-us trade conflicts on the energy sector. China Economic Review, 58, 101360. https://doi.org/10.1016/ j.chieco.2019.101360

Xiao, J., Zhou, M., Wen, F., \& Wen, F. (2018). Asymmetric impacts of oil price uncertainty on Chinese stock returns under different market conditions: Evidence from oil volatility index. Energy Economics, 74, 777-786. https://doi.org/10.1016/j.ene co.2018.07.026

Yu, L., Zha, R., Stafylas, D., He, K., \& Liu, J. (2020). Dependences and volatility spillovers between the oil and stock markets: New evidence from the copula and VAR-BEKK-GARCH models. International Review of Financial Analysis, 68, 101280. https://doi.org/10.101 6/j.irfa.2018.11.007 